
\title{
28 Research Square \\ Genotypic and Phenotypic Characterization of Streptococcus Mutans Isolated From Dental Caries
}

\section{Md. Hossain}

University of Dhaka

Sadab Alam

University of Dhaka

Yead Nibir

University of Dhaka

Tahrima Tusty

University of Dhaka

Sayyeed Bulbul

University of Dhaka

Mirajul Islam

University of Dhaka

Mohammad Hossain ( $\nabla$ mshahnoor@du.ac.bd)

Department of Genetic Engineering \& Biotechnology, University of Dhaka, Dhaka-1000, Bangladesh

\section{Research Article}

Keywords: Dental caries, Streptococcus mutans, acidogenicity, acidurity, genotyping

Posted Date: December 29th, 2020

DOl: https://doi.org/10.21203/rs.3.rs-132779/v1

License: (c) (i) This work is licensed under a Creative Commons Attribution 4.0 International License. Read Full License 


\section{Abstract}

Background: Streptococcus mutans, considered as principal causative agent of dental caries, maintains a biofilm lifestyle in the dental plaque. The oral cavity harbors numerous $S$. mutans strains which displayed remarkable genotypic and phenotypic diversity. This study evaluated the genotypic and phenotypic diversity of $S$. mutans strains isolated from patients with dental caries and compared with the universal reference strain UA159.

Methods: Selective cultivation on mitis-salivaries-bacitracin agar and species-specific polymerase chain reaction (PCR) was carried out to isolate and identify the 209 S. mutans isolates from 336 patients with dental caries. Arbitrarily primed polymerase chain reaction (AP-PCR), PCR amplification of specific gene, acid production, biofilm formation capacity, and deferred antagonism bacteriocin assay were performed to evaluate the genotypic and phenotypic variation. All statistical analysis was performed using the SPSS software version 20 (SPSS, Chicago, IL, USA).

Results: Our study revealed a high degree of genotypic and phenotypic variability among the clinical strains. We observed significant differences in colony morphology, generation time, biofilm formation, bacteriocin and acid production while growing in culture medium. All the clinical isolates were able to lower $\mathrm{pH}$ while growing in Todd-Hewitt broth. Consistent with phenotypic variations, we also observed genotypic variation by AP-PCR and gene specific PCR. AP-PCR analysis suggested that most of the patients with dental caries have distinct type of $S$. mutans strains. Genes related to various two component systems were highly conserved among the isolated strains, however, bacteriocin encoding genes such as $n / m A B, n / m C$ were absent in nearly half of the clinical isolates.

Conclusions: Our study highlights the genotypic and phenotypic diversity of $S$. mutans clinical isolates and indicates the presence of diverse mechanism to initiate and establish the biofilm lifestyle which leads to tooth decay.

\section{Background}

The initiation and successful development of dental caries is caused by multiple bacterial and host factors, such as the composition and biochemical activity of the biofilm organisms, dietary habit, genetic constitution and behavior of the host, tooth architecture and exposure to fluoride [1-4]. The mutans streptococci, specifically $S$. mutans, are considered to be the primary causative agents of dental caries, commonly known as tooth decay $[5,6]$. In addition, several recent studies have reported the associations of certain sub-groups of $S$. mutans with cardiovascular disease. The ability to form biofilm on tooth surface, production of organic acid from various carbohydrates (acidogenicity), ability to survive at low $\mathrm{pH}$ (acidurance), outstanding ability to outcompete other bacteria by the production of bacteriocin and the adaptation to rapidly changing environment can be attributed as the major virulence factors of $S$. mutans [7-13]. Development of natural competence, which is coordinately regulated with the bacteriocin 
production, is another vital attribute that provides genetic diversity to $S$. mutans for niche adaptation and colonization [14-16].

Strains belong to the species, $S$. mutans, are generally classified into four (c, e, f, and k) serological groups based on the composition of cell-surface rhamnose-glucose polysaccharides $[17,18]$. Strains belonged to serotype $c$ are the most abundant in the oral cavity $(70-80 \%)$, followed by serotype e (20\%) and serotype $f$ or serotype $k(2-5 \%)[1,19]$. However, serotype $k$ is more prevalent in heart valves and atheromatous plaques (12\%) than in the oral cavity [20]. Previously, several attempts have been made to correlate the caries incidence with certain genotypes of $S$. mutans, however, no co-relation was observed among multiple studies [16, 21-24]. Furthermore, no relationship was found between the caries status of an individual and the distribution of 41 putative virulence genes or genetic elements in 33 S. mutans isolates [25]. However, several genes have been identified as the virulence attributes and a connection with virulence has been indicated by experiments based on gene inactivation followed by in vitro assays [26-29] or by virulence testing in animal models [30-32].

Restriction fragments length polymorphism (RFLP) based fingerprinting [33, 34], multilocus sequence typing (MLST) [35, 36], comparative genome hybridization [37] and the comparison of whole genome sequencing $[38,39]$ have revealed the prominent intraspecies genetic variability of $S$. mutans.

Additionally, several studies have demonstrated the genetic variability of $S$. mutans in individual genes $[40,41]$. S. mutans strains also display phenotypic variability in accordance with the variation in their genetic repertoire $[19,24,42,43]$. This is especially important for $S$. mutans, which is naturally competent bacterium and therefore has the potential for rapid genome diversification through horizontal gene transfer [44]. In a previous study, Palmer et al. observed a high degree of phenotypic variability among 15 of the completed draft genomes of 57 geographically and genetically diverse isolates of $S$. mutans [1]. Nevertheless, further studies are necessary to get more insights into the genotypic and phenotypic variation among clinically relevant $S$. mutans isolates.

The aim of the present study was to investigate the genotypic and phenotypic heterogeneity of $209 \mathrm{~S}$. mutans strains isolated from 336 patients with dental caries from Bangladesh. We found that $S$. mutans strains isolated from dental caries have high level of genotypic and phenotypic heterogeneity.

\section{Methods}

Study population: Samples were collected from the plaque surface of 336 patients of different age (from 15 to 67 years) and sex groups with dental caries in this study. The study protocol for human subjects was approved by the Institutional Review Board of the Faculty of Biological Sciences, University of Dhaka (Ref. No. 82/Biol.Scs). An informed written consent was taken from each participant. General physiological information of the patients was collected by interview. All methods were performed in accordance with relevant guidelines and regulations. All the patients did not have any chronic diseases. Patients who had taken antibiotic therapy for the last two weeks were excluded from the study. 
Bacterial culture and growth: Oral samples were collected from plaque surface of patients with dental caries using sterile toothpick and suspended in $1 \mathrm{ml}$ phosphate buffer saline (PBS) buffer. $100 \mu \mathrm{l}$ of the sample was spread on the mitis salivarius agar supplemented with $0.5 \mathrm{IU} / \mathrm{mL}$ bacitracin (Sigma, USA) and incubated at microaerophilic condition at $37^{\circ} \mathrm{C}$ for 48 hours. All strains were stored in $40 \%$ glycerol at $-80^{\circ} \mathrm{C}$ and freshly streaked on THY agar before each experiment. Streptococcus strains were routinely grown in Todd-Hewitt medium (HiMedia, India) supplemented with $0.2 \%$ yeast extract (THY) at $37^{\circ} \mathrm{C}$. For the monitoring of growth, overnight cultures were diluted into fresh medium (1:100), grown to late exponential phase and absorbance was taken at $630 \mathrm{~nm}$ at various time interval.

Identification of $S$. mutans strains: Colony morphology on the mitis salivarius-bacitracin agar medium (MSB) was primarily used for the selection of $S$. mutans [45]. Presumptive $S$. mutans colonies were further verified by catalase test and hemolysis on blood agar plate and confirmed by PCR with previously reported species-specific primers targeting Smu.479, which encode DNA-directed RNA polymerase subunit omega, rpoZ (Additional Table 1) [46]. Three colonies of $S$. mutans per individual were selected from MSB plate and preserved at $-80^{\circ} \mathrm{C}$ for later genotypic and phenotypic characterization. However, a single isolate from each patient was investigated in this study. Species-specific PCR was performed by colony PCR. Briefly, a single colony was picked from the THY agar plate and the cells were suspended directly into PCR mixture in a microcentrifuge tube. The PCR assay included 30 cycles of denaturing at $95^{\circ} \mathrm{C}$ for 30 seconds, annealing at $50^{\circ} \mathrm{C}$ for 45 seconds and extension at $72{ }^{\circ} \mathrm{C}$ for $1 \mathrm{~min}$. The amplicon was run in 1.5\% agarose gel containing ethidium bromide and checked for the appropriate bands under UV transilluminator.

Typing of clinical isolates by AP-PCR: The genetic diversity of $S$. mutans isolates was analyzed by arbitrarily primed PCR (AP-PCR) by using the primers set OPA 02 (5'-TGCCGAGCTG-3') and OPA 13 (5'CAGCACCCAC-3') as described previously [16]. The colony PCR was performed using 2X PCR master mix under the conditions of 35 cycles of denaturation at $94{ }^{\circ} \mathrm{C}$ for 30 seconds, annealing at $32{ }^{\circ} \mathrm{C}$ for 1.5 minutes, extension at $72{ }^{\circ} \mathrm{C}$ for 2 minutes, with initial denaturation at $95^{\circ} \mathrm{C}$ for 5 minutes, and a final extension at $72{ }^{\circ} \mathrm{C}$ for 10 minutes. The amplicons generated by AP-PCR were then separated by $1.5 \%$ agarose gel electrophoresis. The molecular size of each bands was calculated and a dendrogram was generated using the UPGMA cluster analysis and analyzed by using the Dice coefficient (>95\%) in accordance with Mitchell et al. [47].

PCR amplification of virulence genes: The detection of $n / m A, n / m B, n / m C$, smu.925, comC,comD comE, gtfB, gbpA, vick, ciaH, cnm, cbp, atp, and Smu.1906 was performed by colony PCR using primers specific to gene based on the UA159 genome sequence (additional Table-1). In addition to the strains being tested, purified genomic DNA from S. mutans UA159 was used as a positive control and distilled water was used as a negative control in each PCR. The PCR products were analyzed by electrophoresis in a $1.5 \%$ agarose gel. gyrA gene was used as an internal control.

Biofilm assay: For biofilm assay, overnight grown bacteria in THY broth were diluted 1:20 and inoculated into fresh THY medium supplemented with $1 \%$ sucrose into wells of polystyrene flat-bottom 24 -well 
microtiter plate and incubated for $48-\mathrm{hr}$ at $37^{\circ} \mathrm{C}$ in microaerophilic condition. After incubation, the culture medium was decanted, and the wells were washed three times with distilled water and stained with $1 \%$ crystal violet for ten minutes. The plates were further washed with distilled water twice to remove the unabsorbed dye. The cells were then resuspended into 1-ml 95\% ethyl alcohol and absorbance was taken at $550 \mathrm{~nm}$. Each experiment was performed in triplicates.

Investigation of the acidurity of $S$. mutans: To investigate the acidurity of $S$. mutans strains, overnight grown bacterial cultures were diluted to 1:50 into THY broth as control or THY broth acidified with $\mathrm{HCl}(\mathrm{pH}$ 5.0) in 96 well microtiter plate and incubated at $37^{\circ} \mathrm{C}$ and the growth was monitored for 20-hour at $630 \mathrm{~nm}$ using a microplate reader (Micro Read 1000, ELISA plate analyzer, Global Diagnostics, Belgium).

Acidogenesis of $S$. mutans clinical isolates: In order to investigate the acid production capacity of the clinical isolates, overnight grown S. mutans culture was inoculated in $10 \mathrm{ml}$ of THY broth (pH 8.32) and the $\mathrm{pH}$ was determined at different time intervals (0-hr, 24-hr, 48-hr and 72-hr) using a pH meter. Each experiment was performed in triplicate.

Deferred antagonism bacteriocin assay: To investigate the bacteriocin production by the clinical isolates, isolated colonies were stabbed into THY agar plates with a toothpick and grown overnight ( 18-hr) at $37^{\circ} \mathrm{C}$ under microaerophilic conditions. Indicator strains were grown to mid exponential growth phase in THY broth and $0.4 \mathrm{ml}$ of the indicator culture (S. pyogenes SN15 and Lactococcus lactis SN24; locally isolated) was mixed with $10-\mathrm{ml}$ of soft agar and overlaid on agar plates that were stabbed with the tester strains. Overlaid plates were then incubated overnight under same conditions and the diameter of the zones of inhibition around the mutacin-producing strains was measured.

Statistical analysis: All continuous variables were summarized in terms of means \pm SD and categorical variables in terms of percentages. To examine whether mean of the quantitative variables of the strains is different from the reference value, one sample student's t-test was performed. Chi-square test was employed to assess the association between qualitative variables and the study groups (disease outcome). Correlation coefficient between two quantitative variables was also computed to know the strength of the relationship between them. Finally, the association of various phenotypic traits with caries status was explored using box plot. For all tests, a probability $(P)$ of $<0.05$ has been considered as significant. All statistical analysis was performed using the SPSS software version 20 (SPSS, Chicago, IL, USA).

\section{Results}

Dental health analysis of study subjects: The DMFT (decay-missing-filled-Teeth) index is widely used to assess the epidemiology of dental caries status. The mean DMFT values of this study was 4.82 with standard deviation of $2.19(n=336)$. The mean age of the study populations was 42.4 and 38.6 for male and female, respectively. Among the 336 patients, $61.6 \%$ was male and $38.4 \%$ female. Physiological characteristics of the patients with colonization of $S$. mutans are presented in Table 1. 
Table 1

Physiological description of the study population.

\begin{tabular}{|lll|}
\hline Characteristics & Male & Female \\
\hline Number of subjects & $207(61.6 \%)$ & $129(38.4 \%)$ \\
\hline Mean Age & 42.4 & 38.6 \\
\hline DMFT index & $5.2 \pm 2.8$ & $4.4 \pm 2.5$ \\
\hline
\end{tabular}

Isolation and identification of $S$. mutans clinical strains: In our study, we used mitis-salivarius-bacitracin (MSB) agar medium to isolate $S$. mutans strains due to high selectivity of this medium for Streptococcus. Based on different colony morphology on MSB medium, colonies were selected for further study. Morphological and cultural characteristics of the isolates ranged from round size blue colonies with granular frosted glass appearance to round, blue, rough and shiny colonies (supplementary Fig. 1). There was also spherical form, raised or convex elevation and black color ranging from a pinpoint to pinhead size with a rough surface, flat, light blue or dark colonies on the MSB agar plate. Pinpoint colony with granular, frosted glass appearance was primarily selected as $S$. mutans. All the strains displayed positive Gram staining reaction and catalase negative (data not shown). However, they exhibited either alpha or gamma hemolysis pattern on blood agar (data not shown). Colony PCR with species-specific primers further confirmed the isolates as S. mutans since the expected product size of SMU.479 was found in agarose gel after electrophoresis (data not shown). The prevalence of $S$. mutans was $81.84 \%$ ( 275 of 336) in patients suffering from dental caries based on colony morphology and biochemical analysis. 209 of 275 colonies $(76 \%)$ of the preliminary identified colonies were finally confirmed as S. mutans by specific-species PCR. The summary of the results for various characteristics of the selected strains has been presented in Table 2 and supplementary Table 2. 
Table 2

Summary of the results for various phenotypic characteristics of selected strains (SN01 to SN 30 and rest of the strains are included in supplementary Table 2).

\begin{tabular}{|c|c|c|c|c|c|c|}
\hline $\begin{array}{l}\text { Strain } \\
\text { ID }\end{array}$ & $\begin{array}{l}\text { Patient } \\
\text { dmft } \\
\text { index }\end{array}$ & $\begin{array}{l}\text { Mean doubling } \\
\text { time (min) }\end{array}$ & $\begin{array}{l}\text { Acid } \\
\text { production }^{a}\end{array}$ & $\begin{array}{l}\text { Biofilm } \\
\text { formation }\end{array}$ & $\begin{array}{l}\text { Bacteriocin } \\
\text { against } \\
S . \\
\text { pyogenes }\end{array}$ & $\begin{array}{l}\text { Bacteriocin } \\
\text { against } \\
\text { L. lactis }^{\text {d }}\end{array}$ \\
\hline UA159 & $\mathrm{N} / \mathrm{A}$ & 57 & 6.29 & 0.356 & $16 \mathrm{~mm}$ & $14 \mathrm{~mm}$ \\
\hline SN01 & 7 & 104 & 5.76 & 0.151 & $13 \mathrm{~mm}$ & 0 \\
\hline SN02 & 3 & 85 & 5.26 & 0.6725 & 0 & 0 \\
\hline SN03 & 5 & 94 & 6.54 & 0.2175 & 0 & 0 \\
\hline SN04 & 8 & 43 & 5.22 & 0.1805 & 0 & $15 \mathrm{~mm}$ \\
\hline SN05 & 2 & 58 & 5.84 & 0.7855 & $12 \mathrm{~mm}$ & 0 \\
\hline SN06 & 4 & 101 & 5.67 & 0.2055 & 0 & 0 \\
\hline SN07 & 11 & 91 & 5.37 & 0.996 & 0 & 0 \\
\hline SN08 & 9 & 153 & 5.82 & 0.7885 & 0 & 0 \\
\hline SN09 & 6 & 47 & 6.02 & 0.2385 & 0 & 0 \\
\hline SN10 & 2 & 116 & 5.30 & 0.4335 & 0 & 0 \\
\hline SN11 & 5 & 121 & 5.40 & 0.303 & $15 \mathrm{~mm}$ & 0 \\
\hline SN12 & 1 & 107 & 6.29 & 0.282 & 0 & 0 \\
\hline SN13 & 8 & 59 & 5.96 & 0.1675 & 0 & 0 \\
\hline SN14 & 6 & 81 & 5.10 & 0.819 & 0 & 0 \\
\hline SN15 & 7 & 71 & 6.27 & 0.4675 & 0 & 0 \\
\hline SN16 & 2 & 71 & 5.90 & 0.376 & 0 & 0 \\
\hline SN17 & 3 & 51 & 5.50 & 0.4915 & 0 & 0 \\
\hline SN18 & 10 & 86 & 5.60 & 0.2725 & 0 & 0 \\
\hline
\end{tabular}

aindicates the final $\mathrm{pH}$ of the growth medium after 72 hour incubation.

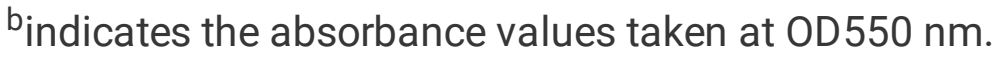

czones of inhibition in diameter against $S$. pyogenes.

${ }^{d}$ zones of inhibition in diameter against $L$. lactis. 


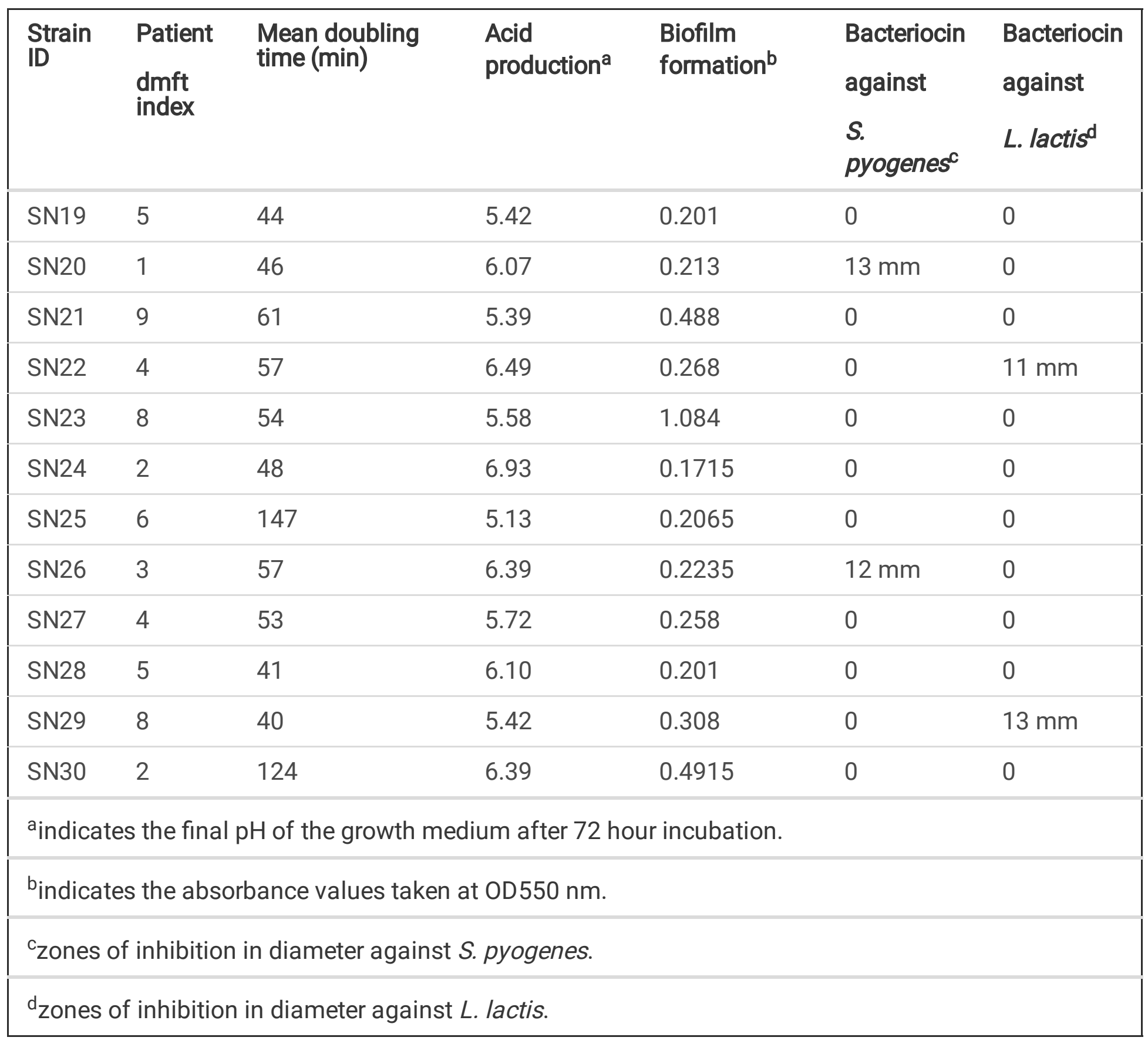

Genotypic diversity of $S$. mutans isolates: In order to get an idea about genotypic diversity of the isolated strains, we performed AP-PCR for all 209 S. mutans strains. Figure 1a demonstrates the AP-PCR patterns carried out with OPA-02 and OPA-13 primers using some representative isolates, where we observed different spectrum of amplicons for each isolate, which indicates the high level of genetic polymorphism among the isolated strains. The results of AP-PCR analysis of the first 40 isolates revealed that 26 different genotypes were present among the strains. After analysis of dendrogram of the selected strains, 10 different clusters were observed in our study (Fig. 1b).

Growth kinetics of $S$. mutans clinical isolates: To investigate the growth kinetics of various clinical isolates, we performed the growth curve analysis for 12 hours. Compare to the reference strain UA159, we observed noticeable variation in growth rate in some strains, however, most of the strains grew at similar rate to UA159 (Fig. 2a, 2b and supplementary Table 2). Some of the isolates demonstrated very slow 
growth rate with long dividing time (>150 minutes) and took three to four days to have distinct colony on the agar plate at microaerophilic condition. Growth pattern of the UA159 was in the middle among the isolated strains (dividing time 57 minutes). The mean doubling time of the isolated strains were 75.12 (standard deviation of 24.92 ) with $95 \%$ confidence interval [14.81, 21.63].

Distribution of $S$. mutans putative virulence genes: We investigated the presence or absence of 15 chromosomally encoded $S$. mutans virulence genes by PCR. Genes involved in various functions such as two component system, bacteriocin production, biofilm formation, acid tolerance, and collagen binding were investigated in this study (Table 3, supplementary Table 2). Eight of these genes were present in all clinical isolates and five genes were differentially present among the isolates. However, collagen binding protein, $c n m$ and $c b p$, were not detected in the isolates. The presence of bacteriocin encoding genes $(n / m A B$ and $n / m C$ ) was observed in $63 \%$ and $48 \%$ of the isolates. We also studied the distribution of two component system ComDE and CiaHR and we found that both systems are present in all of the isolated strains. 
Table 3

Distribution of virulence genes among S. mutans clinical isolates.

\begin{tabular}{|lll|}
\hline Locus & Virulence trait/function & $\begin{array}{l}\text { \% of clinical isolates with expected size } \\
\text { PCR product }\end{array}$ \\
\hline gtfB & $\begin{array}{l}\text { Glucosyltransferases GTF-I Biofilm } \\
\text { formation }\end{array}$ & 100 \\
\hline gbpA & $\begin{array}{l}\text { Glucan-binding protein A, Biofilm } \\
\text { formation }\end{array}$ & 100 \\
\hline cbp & Collagen binding protein & 0 \\
\hline atpA & Collagen binding protein & 0 \\
\hline vicK & $\begin{array}{l}\text { F-ATPase proton pump, Acidogenesis or } \\
\text { acidurity }\end{array}$ & 100 \\
\hline TtrA & Protease enzyme or chaperone & 100 \\
\hline$n l m A B$ & Bacteriocin production (mutacin IV) & 63 \\
\hline$n l m C$ & Bacteriocin production (mutacin V) & 48 \\
\hline Smu.1906 & Bacteriocin production & 72 \\
\hline Smu.152 & Bacteriocin immunity protein & 63 \\
\hline comC & Bacteriocin inducing peptide & 72 \\
\hline comD & Sensor kinase for bacteriocin production & 100 \\
\hline comE & $\begin{array}{l}\text { Response regulator for bacteriocin } \\
\text { production }\end{array}$ & 100 \\
\hline ciaH & Two component system and acidurity & 100 \\
\hline
\end{tabular}

Acid tolerance by $S$. mutans clinical isolates: The ability to grow at low $\mathrm{pH}$ is an important virulence attribute for $S$. mutans. To investigate the acid tolerance of S. mutans clinical isolates, we cultured the isolated strains in the medium which was acidified at $\mathrm{pH} 5.0$ with $\mathrm{HCl}$. We observed noticeable reduction in growth compared to growth at $\mathrm{pH} 8.3$ for every strains (Fig. 3, supplementary table 2). While some strains faced difficulty to grow at pH 5.0, some strains grew faster than UA159. Mean growth of the clinical isolates at pH 5.0 for 20-hour at absorbance $630 \mathrm{~nm}$ was 0.66 with standard deviation of 0.22 . The variation of the strains was significant $(p<0.001 ; 95 \% \mathrm{Cl}=[-0.171,-0.112])$.

Acidogenesis of $S$. mutans clinical isolates: Acidogenesis is the most important virulence factor for dental caries. To investigate the acid production capacity of the clinical isolates, we inoculated the overnight grown S. mutans culture in THY broth and measured the $\mathrm{pH}$ value at different time intervals. We noticed that all of the clinical isolates have remarkable ability to produce acid while growing in THY broth 
(Table 2 and Fig. 4 and supplementary Table 2) and turned the initial pH of the media from 8.34 to more acidic $\mathrm{pH}$ (up to $\mathrm{pH}$ 5.0). Most of the clinical isolates displayed better acid production ability than the reference strain, UA159 which has turned the THY broth from $\mathrm{pH} 8.34$ to $\mathrm{pH}$ 6.25. Mean pH value after 72hour growth was 5.7 with standard deviation of 0.355 . Two-tailed analysis suggested significant variation among the clinical isolates $(p<0.001,95 \% \mathrm{Cl}=[0.637,0.539])$.

Biofilm forming capacity of $S$. mutans clinical isolates: $S$. mutans has the outstanding ability to form biofilm on the teeth surface and causes plaque formation. In order to study biofilm forming capacity of various clinical isolates, we cultured them in THY medium supplemented with $1 \%$ sucrose for 48 hours in 24 well plates. Our in vitro biofilm formation assay suggested that all the strains retained significant level of biofilm formation capacity as like UA159. However, variation in biofilm formation capacity was also present among the clinical strains and some of the isolates displayed superior biofilm forming capacity than UA159 (Table 2, supplementary Table 2 and Fig. 5). The mean biofilm forming capacity was 0.521 with standard deviation of 0.256 . Further statistical analysis revealed significant variations among mean of the strains with reference UA159 $(P<0.001 ; 95 \% \mathrm{Cl}=0.126,0.196)$.

Bacteriocin production by different clinical isolates: $S$. mutans has the capacity to produce various types of bacteriocins to inhibit other competitor microorganisms present in the oral habitat [5]. To investigate the ability of different $S$. mutans clinical isolates to produce bacteriocins, we screened all $S$. mutans isolates against S. pyogenes (locally isolated) and L. lactis (locally isolated). Our study revealed that $11 \%$ and $9.56 \%$ of the clinical isolates were able to secrete bacteriocin against locally isolated $S$. pyogenes and L. lactis respectively (Supplementary Table 2 and Fig. 6). Whereas, S. mutans UA159 produced antagonistic activity against both indicator bacteria.

\section{Discussion}

Oral health is generally considered as a mirror of one's general health and sometimes associated with several systemic diseases [48]. Dental caries, commonly known as tooth decay, is the most common oral health problem worldwide and $S$. mutans is considered to be the primary causative agents of dental caries [49]. S. mutans resides in the dental plaque, a multispecies biofilm community that harbors more than 700 different types of microorganisms [50]. As the biofilm matures, the pioneer colonizers, which are comprised mostly of mitis streptococci, are replaced with early colonizers, such as $S$. mutans [51]. The ability to establish biofilm lifestyle, production of organic acid and ability to survive at low $\mathrm{pH}$, outstanding ability to outcompete other bacteria by the production of bacteriocin and generation of genetic diversity by natural transformation are attributed as the prime driving force for its ability to adapt and survive in the rapidly changing environment of the oral cavity $[7-11,14]$. In this study, we show that the phenotypic and genotypic properties that are associated with the virulence of $S$. mutans are diverse and vary significantly among 209 newly isolated clinical strains.

We found that types and colony morphology of the isolated strains on mitis salivarius agar vary considerably from patient to patient. We observed multiple strains in the same sample with various 
colony morphology, which further confirmed that dental plaques indeed contain multispecies biofilm structures and intimate association of all the species are required for causing dental caries.

We also performed AP-PCR of first 40 strains to investigate the genotypic diversity of the isolated strains and found that 26 different genotypes are present among the strains. High levels of genotypic variations were also found previously by several groups $[16,52,53]$. Zhou et al. classified $730 \mathrm{~S}$. mutans isolates into 337 distinct genotypes by AP-PCR fingerprint analysis [52]. In a study with young adults, Emanuelsson et al. [54] noticed only seven genotypes in subjects who had previously experienced dental caries. Napimoga et al. found eight genotypes in caries-active subjects using AP-PCR [55]. However, it has been reported that children harbor only one to five distinct genotypes of $S$. mutans [16]. The high prevalence of genotypic variations can be attributed to diversified horizontal gene transfer, various nutritional behavior, and chemical environment in the oral cavity.

As like the genotypic diversity, our phenotypic studies revealed that isolated $S$. mutans strains have wide variation in phenotypic diversity. Ability to form biofilm, to sustain the growth at low $\mathrm{pH}$ and production of acids are considered as key virulence factors in S. mutans and were studied extensively [1]. We observed high variability of these virulence factors among the isolated strains. Some strains displayed better sucrose-dependent biofilm forming capacity than the universal reference strain, UA159 (Fig. 5) and some were crippled in biofilm forming capacity. Biofilm formation capacity of $S$. mutans is aided by various genes, which encode several surface antigens to attach the teeth surface [56,57]. The variation in biofilm forming capacity can be due to the presence or absence of various biofilm associated genes, prevalence of polymorphism among these genes and differential epigenetic regulation. We also investigated the presence of biofilm associated gene, $g b p A$ in the clinical isolates, however, this gene was present in all strains.

Acid resistance of $S$. mutans strains is conferred by the $\mathrm{F}_{1} \mathrm{~F}_{0^{-}} \mathrm{H}^{+}$-translocating ATPase and the activity and optimum $\mathrm{pH}$ of this ATPase enzymes are correlated with acid tolerance of oral bacteria [58]. For instance, lactobacilli which are strong aciduric organism exhibit better activity and lower $\mathrm{pH}$ optima for the ATPase than the acid-sensitive species, $S$. sanguinis [59]. Our results suggest that isolated strains have differential response to acid stress. Most of the clinical strains suffered from growth constraints and individual strain exhibited distinct growth kinetics at pH 5.5 (Fig. 3). In addition to acidurity, we also investigated the acidogenesis character of the isolated strains and found noticeable variation among acid production while growing on THY media. However, all the strains could turn the initial medium $\mathrm{pH}$ of 8.32 to more acidic $\mathrm{pH}$ from 5.02 to 6.54 . A large proportion of the clinical isolates displayed better acid production than UA159 although some of the strains were either equal or poor acidogenic as like UA159. Our results showed little variation from a previous study where equal acidogenicity was observed among the $S$. mutans isolates [60]. The apparent variation in acid production may be due to different methods and growth medium used in the studies. When we assessed the correlation of acid production with status of dental caries, we did not find any correlation between acidogenicity and tooth decay status (data not shown). 
Production of bacteriocins to inhibit closely related bacteria are assumed to be important virulence attributes in $S$. mutans, which encodes several bacteriocin encoding genes to inhibit the growth of various bacteria in vitro [8]. Mutacin IV and V are two important non-lantibiotic bacteria produced by $S$. mutans to inhibit S. pyogenes, S. gordonii, S. oralis, L. lactis and other streptococci [5]. In this study, we tested the clinical isolates against $S$. pyogenes and L. lactis by deferred antagonism bacteriocin assay and observed a wide variation in bacteriocin production. Although a minor fraction $(11 \%$, and $9.56 \%$ respectively) was able to display antagonistic activity, both $n / m A B$ and $n / m C$ genes were present in $63 \%$ and $48 \%$ of the isolates. This is in agreement with previous studies, which found the mutacin IV encoding $\mathrm{n} / \mathrm{mA}$ and $\mathrm{n} / \mathrm{mB}$ genes in $50 \%$ of a population of 70 clinical isolates (31) and $n / \mathrm{mC}$ was found in $60 \%$ of the isolates $[14,25]$.

Previous genetics and biochemical study indicated that the buildup of a processed form of $\operatorname{comC}$ gene product (CSP) results in activation of a two-component system (ComD and ComE), which induces the expression of bacteriocins [8]. In this study, we investigated the presence or absence of $\operatorname{comC}$, comD, and comE genes among the clinical isolates and found that comDE two component systems is present in all the isolates. However, comC was absent in $28 \%$ of the strains, which might be due to either absence of this gene in the isolates or presence of different version of this gene which was not amplified by the primer sequences. Previously, it has been found that significant numbers of the sequenced strains either lack the comCDE genes or contained various mutations that could lead to failure to produce functional ComCDE proteins $[61,62]$.

In this study, we also investigated the distribution of several putative virulence genes with an aim to identify the genetic elements associated with observed phenotypes. Although the presence or absence of the genetic elements tested did not correlate with caries status, their distribution was strongly associated with the virulent phenotypes. For example, strains lacking $n / m A B, n / m C$ or $c o m C$ genes were unable to display antagonistic activity against the indicator bacteria. In addition, some strains with $n / m A B, n / m C$ or comC genes were also unable to display antagonistic activity against the indicator bacteria. This might be due to the presence of bacteriocin immunity protein, lack of specific target protein in the indicator bacteria or the mutation in bacteriocin transporter or signaling molecules involved in quorum sensing pathway. IN our study we found that most of the strains are genetically homogenous for genes associated with two-component systems which is in accordance with a previous report which reported a significant level of genetic homogeneity among $S$. mutans strains [25]. However, our results are in contrast with Palmer et al. who reported that wide variations exist among strains of $S$. mutans in the pathways involved in quorum sensing, genetic competence and non-lantibiotic bacteriocins [1]. Variation in the same species is prevalent in several bacterial species, either by sharing genes by some but not all isolates or by strain-specific genes that are unique to each isolates [25, 63]. In a genome wide comparison, it was revealed that $S$. mutans strains, UA159 and NN2025, differ in $10 \%$ of the genes and $20 \%$ of the open reading frames (ORFs) [39].

The phenotypic and genotypic properties of $S$. mutans clinical isolates presented here imply that clinical strains have undergone intense evolutionary changes to cope up with the rapidly changing environment 
in the oral cavity. Further genomics and transcriptomics studies are warranted to get insight into the tremendous variation exists among the $S$. mutans clinical isolates and their possible interactions with symbiotic and antagonistic neighbors prevalent in the oral cavity. It would also be worthwhile to employ metagenomic approaches to understand the complex architecture of dental caries associated microbiome and their ability to cause tooth decay.

\section{Conclusions}

Taken together, our results indicated that $S$. mutans clinical isolates exhibit profound variations in both genotypic and phenotypic characteristics and highlighted the presence of diverse mechanism to cause dental caries. This study has helped us to better understand the cariogenic variations of $S$. mutans clinical strains which can be used to devise new approaches to control $S$. mutans mediated dental diseases thereby. Moreover, the obtained knowledge from this study can be used as a resource to further study the pathogenesis of this bacterium in relation with dental caries and other systemic diseases.

\section{Abbreviations}

AP-PCR

Arbitrarily primed polymerase chain reaction; MSB:mitis-salivaries-bacitracin; THY:Todd-Hewitt yeast extract.

\section{Declarations}

Ethics Approval and Consent to Participate

The study protocol for human subjects was approved by the Institutional Review Board of the Faculty of Biological Sciences, University of Dhaka (Ref. No. 82/Biol.Scs). An informed written consent was taken from each participant.

Consent for Publication

All authors have given the consent to publish this manuscript.

Availability of Data and Materials

All data are included with this manuscript.

Competing Interests

We state that there is no conflict of interest exists in this manuscript.

Funding 
This work was supported by research grant provided to Dr. Mohammad Shahnoor Hossain from Biotechnology Research Centre, University of Dhaka Bangladesh.

Authors' Contribution

Conceived and designed the experiments: MSH. Performed experiments: MSH, SA, YMN, TAT, SMB. Analyzed the data: MSH, MSH, SA, YMN, TAT, SMB. Performed statistical analysis, MI. Wrote the manuscript: MSH. Agreed with manuscript results and conclusions: MSH, SA, YMN, TAT, SMB, MI and MSH. Made critical revisions and approved final version: $\mathrm{MSH}$. All authors reviewed and approved the final manuscript.

Acknowledgements

We thank Dr. Shahidul Islam of University Dental College, Dhaka for his help collect the sample and dental examination.

\section{References}

1. Palmer SR, Miller JH, Abranches J, Zeng L, Lefebure T, Richards VP, Lemos JA, Stanhope MJ, Burne RA: Phenotypic heterogeneity of genomically-diverse isolates of Streptococcus mutans. PLoS One 2013, 8(4):e61358.

2. Kuramitsu HK, He X, Lux R, Anderson MH, Shi W: Interspecies interactions within oral microbial communities. Microbiology and molecular biology reviews : MMBR 2007, 71(4):653-670.

3. Levine M: Susceptibility to dental caries and the salivary proline-rich proteins. International journal of dentistry 2011, 2011:953412.

4. Kleinberg I: A mixed-bacteria ecological approach to understanding the role of the oral bacteria in dental caries causation: an alternative to Streptococcus mutans and the specific-plaque hypothesis. Crit Rev Oral Biol Med 2002, 13(2):108-125.

5. Hossain MS, Biswas I: Mutacins from Streptococcus mutans UA159 are active against multiple streptococcal species. Appl Environ Microbiol 2011, 77(7):2428-2434.

6. Bowden GH: Microbiology of root surface caries in humans. Journal of dental research 1990, 69(5):1205-1210.

7. Hossain MS, Biswas I: SMU.152 acts as an immunity protein for mutacin IV. Journal of bacteriology 2012, 194(13):3486-3494.

8. Hossain MS, Biswas I: An extracelluar protease, SepM, generates functional competence-stimulating peptide in Streptococcus mutans UA159. J Bacterio/ 2012, 194(21):5886-5896.

9. Guo L, He X, Shi W: Intercellular communications in multispecies oral microbial communities. Frontiers in microbiology 2014, 5:328.

10. Bowen WH, Koo H: Biology of Streptococcus mutans-derived glucosyltransferases: role in extracellular matrix formation of cariogenic biofilms. Caries Res 2011, 45(1):69-86. 
11. Belli WA, Marquis RE: Adaptation of Streptococcus mutans and Enterococcus hirae to acid stress in continuous culture. Appl Environ Microbiol 1991, 57(4):1134-1138.

12. Guo L, Hu W, He X, Lux R, McLean J, Shi W: investigating acid production by Streptococcus mutans with a surface-displayed pH-sensitive green fluorescent protein. PLoS One 2013, 8(2):e57182.

13. Banas JA: Virulence properties of Streptococcus mutans. Front Biosci 2004, 9:1267-1277.

14. Kreth J, Merritt J, Shi W, Qi F: Co-ordinated bacteriocin production and competence development: a possible mechanism for taking up DNA from neighbouring species. Molecular microbiology 2005, 57(2):392-404.

15. Kreth J, Merritt J, Shi W, Qi F: Competition and coexistence between Streptococcus mutans and Streptococcus sanguinis in the dental biofilm. J Bacterio/ 2005, 187(21):7193-7203.

16. Pieralisi FJ, Rodrigues MR, Segura VG, Maciel SM, Ferreira FB, Garcia JE, Poli-Frederico RC: Genotypic Diversity of Streptococcus mutans in Caries-Free and Caries-Active Preschool Children. Int J Dent 2010, 2010:824976.

17. Nakano K, Ooshima T: Serotype classification of Streptococcus mutans and its detection outside the oral cavity. Future Microbio/ 2009, 4(7):891-902.

18. Tsukioka Y, Yamashita Y, Oho T, Nakano Y, Koga T: Biological function of the dTDP-rhamnose synthesis pathway in Streptococcus mutans. J Bacterio/ 1997, 179(4):1126-1134.

19. Nakano K, Nomura R, Nakagawa I, Hamada S, Ooshima T: Demonstration of Streptococcus mutans with a cell wall polysaccharide specific to a new serotype, $k$, in the human oral cavity. $J$ Clin Microbio/ 2004, 42(1):198-202.

20. Nakano K, Nomura R, Matsumoto M, Ooshima T: Roles of oral bacteria in cardiovascular diseasesfrom molecular mechanisms to clinical cases: Cell-surface structures of novel serotype $k$ Streptococcus mutans strains and their correlation to virulence. J Pharmacol Sci 2010, 113(2):120125.

21. Shibata Y, Ozaki K, Seki M, Kawato T, Tanaka H, Nakano Y, Yamashita Y: Analysis of loci required for determination of serotype antigenicity in Streptococcus mutans and its clinical utilization. $J$ Clin Microbiol 2003, 41(9):4107-4112.

22. Tahmourespour A, Nabinejad A, Shirian H, Rosa EA, Tahmourespour S: Typing of Streptococcus mutans strains isolated from caries free and susceptible subjects by multilocus enzyme electrophoresis. Braz J Microbiol 2013, 44(3):873-877.

23. Phattarataratip E, Olson B, Broffitt B, Qian F, Brogden KA, Drake DR, Levy SM, Banas JA: Streptococcus mutans strains recovered from caries-active or caries-free individuals differ in sensitivity to host antimicrobial peptides. Mol Oral Microbiol 2011, 26(3):187-199.

24. Lembo FL, Longo PL, Ota-Tsuzuki C, Rodrigues CR, Mayer MP: Genotypic and phenotypic analysis of Streptococcus mutans from different oral cavity sites of caries-free and caries-active children. Oral Microbiol Immunol 2007, 22(5):313-319.

25. Argimon S, Caufield PW: Distribution of putative virulence genes in Streptococcus mutans strains does not correlate with caries experience. J Clin Microbiol 2011, 49(3):984-992. 
26. Levesque CM, Mair RW, Perry JA, Lau PC, Li YH, Cvitkovitch DG: Systemic inactivation and phenotypic characterization of two-component systems in expression of Streptococcus mutans virulence properties. Lett Appl Microbiol 2007, 45(4):398-404.

27. Li YH, Tang N, Aspiras MB, Lau PC, Lee JH, Ellen RP, Cvitkovitch DG: A quorum-sensing signaling system essential for genetic competence in Streptococcus mutans is involved in biofilm formation. $J$ Bacteriol 2002, 184(10):2699-2708.

28. Senadheera D, Krastel K, Mair R, Persadmehr A, Abranches J, Burne RA, Cvitkovitch DG: Inactivation of VicK affects acid production and acid survival of Streptococcus mutans. J Bacterio/ 2009, 191(20):6415-6424.

29. Shankar M, Hossain MS, Biswas I: Pleiotropic Regulation of Virulence Genes in Streptococcus mutans by the Conserved Small Protein SprV. J Bacterio/ 2017, 199(8).

30. Munro C, Michalek SM, Macrina FL: Cariogenicity of Streptococcus mutans V403 glucosyltransferase and fructosyltransferase mutants constructed by allelic exchange. Infect Immun 1991, 59(7):2316-2323.

31. Yamashita Y, Bowen WH, Burne RA, Kuramitsu HK: Role of the Streptococcus mutans gtf genes in caries induction in the specific-pathogen-free rat model. Infect Immun 1993, 61(9):3811-3817.

32. Nakano K, Hokamura K, Taniguchi N, Wada K, Kudo C, Nomura R, Kojima A, Naka S, Muranaka Y, Thura $\mathrm{M}$ et al: The collagen-binding protein of Streptococcus mutans is involved in haemorrhagic stroke. Nat Commun 2011, 2:485.

33. Caufield PW, Walker TM: Genetic diversity within Streptococcus mutans evident from chromosomal DNA restriction fragment polymorphisms. J Clin Microbio/ 1989, 27(2):274-278.

34. Kulkarni GV, Chan KH, Sandham HJ: An investigation into the use of restriction endonuclease analysis for the study of transmission of mutans streptococci. Journal of dental research 1989 , 68(7):1155-1161.

35. Do T, Gilbert SC, Clark D, Ali F, Fatturi Parolo CC, Maltz M, Russell RR, Holbrook P, Wade WG, Beighton D: Generation of diversity in Streptococcus mutans genes demonstrated by MLST. PLOS One 2010, 5(2):e9073.

36. Nakano K, Lapirattanakul J, Nomura R, Nemoto H, Alaluusua S, Gronroos L, Vaara M, Hamada S, Ooshima T, Nakagawa I: Streptococcus mutans clonal variation revealed by multilocus sequence typing. J Clin Microbio/ 2007, 45(8):2616-2625.

37. Zhang L, Foxman B, Drake DR, Srinivasan U, Henderson J, Olson B, Marrs CF, Warren JJ, Marazita $\mathrm{ML}$ : Comparative wholegenome analysis of Streptococcus mutans isolates within and among individuals of different caries status. Oral Microbiol Immunol 2009, 24(3):197-203.

38. Ajdic D, McShan WM, McLaughlin RE, Savic G, Chang J, Carson MB, Primeaux C, Tian R, Kenton S, Jia $\mathrm{H}$ et al: Genome sequence of Streptococcus mutans UA159, a cariogenic dental pathogen. ProC Natl Acad Sci U S A 2002, 99(22):14434-14439.

39. Maruyama F, Kobata M, Kurokawa K, Nishida K, Sakurai A, Nakano K, Nomura R, Kawabata S, Ooshima T, Nakai K et al: Comparative genomic analyses of Streptococcus mutans provide insights 
into chromosomal shuffling and species-specific content. BMC Genomics 2009, 10:358.

40. Nomura R, Nakano K, Taniguchi N, Lapirattanakul J, Nemoto H, Gronroos L, Alaluusua S, Ooshima T: Molecular and clinical analyses of the gene encoding the collagen-binding adhesin of Streptococcus mutans. Journal of medical microbiology 2009, 58(Pt 4):469-475.

41. Waterhouse JC, Russell RR: Dispensable genes and foreign DNA in Streptococcus mutans. Microbiology 2006, 152(Pt 6):1777-1788.

42. Balakrishnan M, Simmonds RS, Kilian M, Tagg JR: Different bacteriocin activities of Streptococcus mutans reflect distinct phylogenetic lineages. Journal of medical microbiology 2002, 51(11):941948.

43. Beighton D, Hayday H: The establishment of the bacterium Streptococcus mutans in dental plaque and the induction of caries in macaque monkeys (Macaca fascicularis) fed a diet containing cookedwheat flour. Arch Oral Biol 1984, 29(5):369-372.

44. Willems RJ, Hanage WP, Bessen DE, Feil EJ: Population biology of Gram-positive pathogens: highrisk clones for dissemination of antibiotic resistance. FEMS microbiology reviews 2011, 35(5):872900.

45. Gold OG, Jordan HV, Van Houte J: A selective medium for Streptococcus mutans. Arch Oral Biol 1973, 18(11):1357-1364.

46. Chen Z, Saxena D, Caufield PW, Ge Y, Wang M, Li Y: Development of species-specific primers for detection of Streptococcus mutans in mixed bacterial samples. FEMS Microbiol Lett 2007, 272(2):154-162.

47. Cheon K, Moser SA, Whiddon J, Osgood RC, Momeni S, Ruby JD, Cutter GR, Allison DB, Childers NK: Genetic diversity of plaque mutans streptococci with rep-PCR. Journal of dental research 2011, 90(3):331-335.

48. Daniluk T, Fiedoruk K, Sciepuk M, Zaremba ML, Rozkiewicz D, Cylwik-Rokicka D, Tokajuk G, Kedra BA, Anielska I, Stokowska $\mathrm{W}$ et al: Aerobic bacteria in the oral cavity of patients with removable dentures. Advances in medical sciences 2006, 51 Suppl 1:86-90.

49. Loesche WJ: Role of Streptococcus mutans in human dental decay. Microbiol Rev 1986, 50(4):353380 .

50. Aas JA, Griffen AL, Dardis SR, Lee AM, Olsen I, Dewhirst FE, Leys EJ, Paster BJ: Bacteria of dental caries in primary and permanent teeth in children and young adults. Journal of clinical microbiology 2008, 46(4):1407-1417.

51. Kolenbrander PE, Palmer RJ, Jr., Rickard AH, Jakubovics NS, Chalmers NI, Diaz PI: Bacterial interactions and successions during plaque development. Periodontology 2000 2006, 42:47-79.

52. Zhou Q, Qin X, Qin M, Ge L: Genotypic diversity of Streptococcus mutans and Streptococcus sobrinus in 3-4-year-old children with severe caries or without caries. Int J Paediatr Dent 2011, 21(6):422-431.

53. Dame-Teixeira N, Arthur RA, Parolo CC, Maltz M: Genotypic diversity and virulence traits of Streptococcus mutans isolated from carious dentin after partial caries removal and sealing. ScientificWorld Journal 2014, 2014:165201. 
54. Redmo Emanuelsson IM, Carlsson P, Hamberg K, Bratthall D: Tracing genotypes of mutans streptococci on tooth sites by random amplified polymorphic DNA (RAPD) analysis. Oral microbiology and immunology 2003, 18(1):24-29.

55. Napimoga M.H. KRU, Rosa R. T.: Genotypic diversity and virulence traits of Streptococcus mutans in caries-free and caries-active individuals. Journal of medical microbiology 2004, 53(7):697-703.

56. Bowen WH, Schilling K, Giertsen E, Pearson S, Lee SF, Bleiweis A, Beeman D: Role of a cell surfaceassociated protein in adherence and dental caries. Infection and immunity 1991, 59(12):4606-4609.

57. Zhu L, Kreth J, Cross SE, Gimzewski JK, Shi W, Qi F: Functional characterization of cell-wallassociated protein WapA in Streptococcus mutans. Microbiology 2006, 152(Pt 8):2395-2404.

58. Lemos JA, Burne RA: A model of efficiency: stress tolerance by Streptococcus mutans. Microbiology 2008, 154(Pt 11):3247-3255.

59. Bender GR, Sutton SV, Marquis RE: Acid tolerance, proton permeabilities, and membrane ATPases of oral streptococci. Infection and immunity 1986, 53(2):331-338.

60. De A, Pasquantonio G, Cerroni L, Petrelli D, Lauro D, Longhi M, Vitali LA: Genotypic and phenotypic heterogeneity in Streptococcus mutans isolated from diabetic patients in Rome, Italy. Springerplus 2016, 5(1):1794.

61. Klein MI, Bang S, Florio FM, Hofling JF, Goncalves RB, Smith DJ, Mattos-Graner RO: Genetic diversity of competence gene loci in clinical genotypes of Streptococcus mutans. J Clin Microbio/ 2006, 44(8):3015-3020.

62. Ahn SJ, Wen ZT, Burne RA: Multilevel control of competence development and stress tolerance in Streptococcus mutans UA159. Infect Immun 2006, 74(3):1631-1642.

63. Medini D, Serruto D, Parkhill J, Relman DA, Donati C, Moxon R, Falkow S, Rappuoli R: Microbiology in the post-genomic era. Nature reviews Microbiology 2008, 6(6):419-430.

\section{Figures}

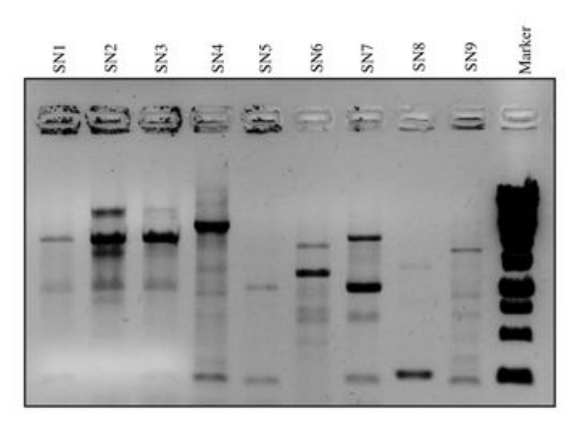

A

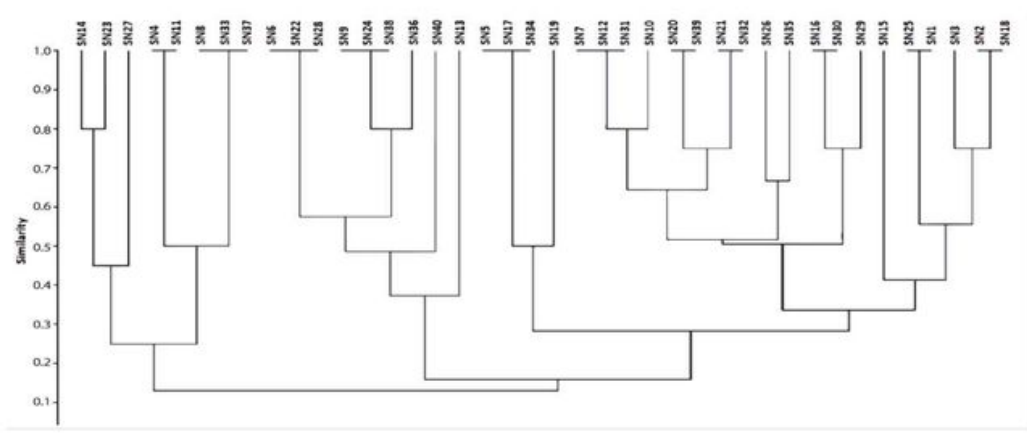

$\mathbf{B}$

Figure 1 
(a) AP-PCR patterns of selected S. mutans isolates. Colony PCR was performed with the primer set OPA02 and OPA-13 primers (lanes 1-9). Lane 10 contains the DNA ladder (1 kbp plus). (b) Dendrogram delineating the genetic diversity of the 40 isolated S. mutans strains. The Dice coefficient was computed based on UPGMA clustering algorithm.

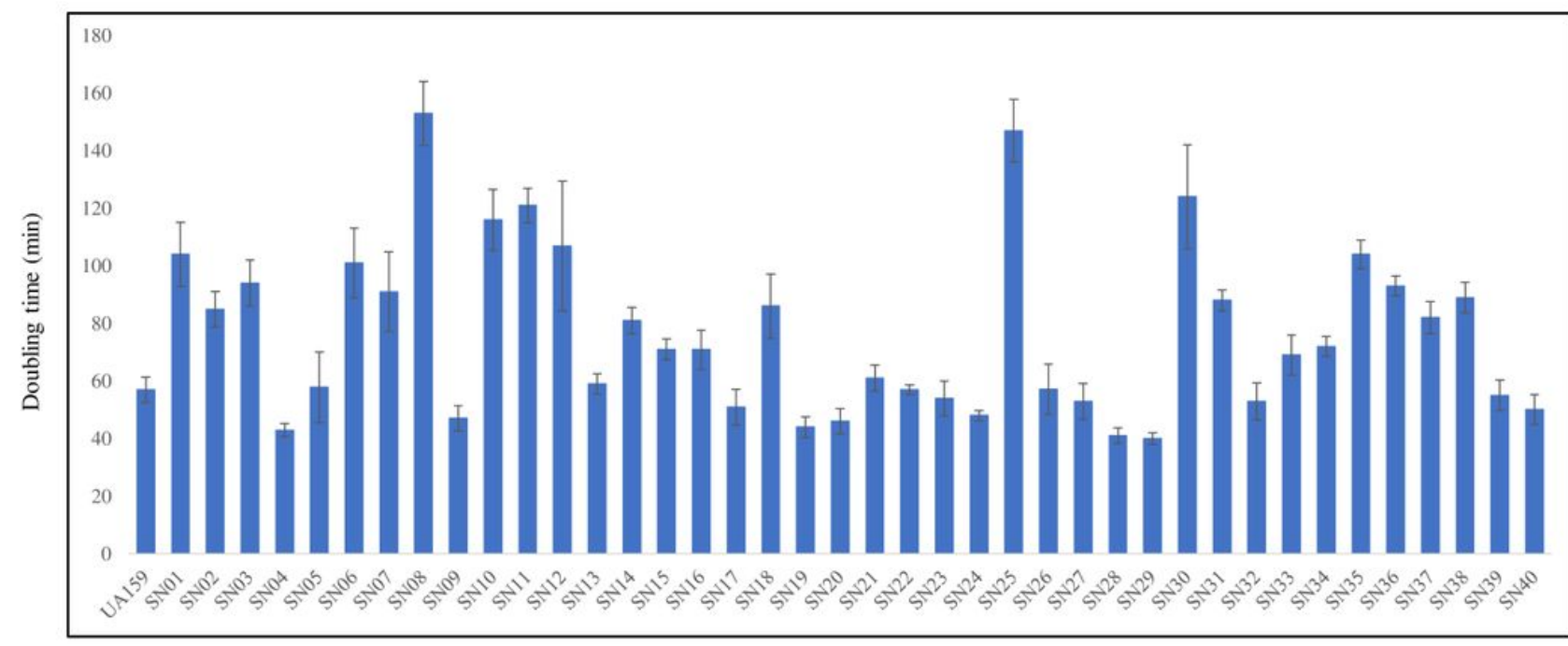

S. mutans strains

A

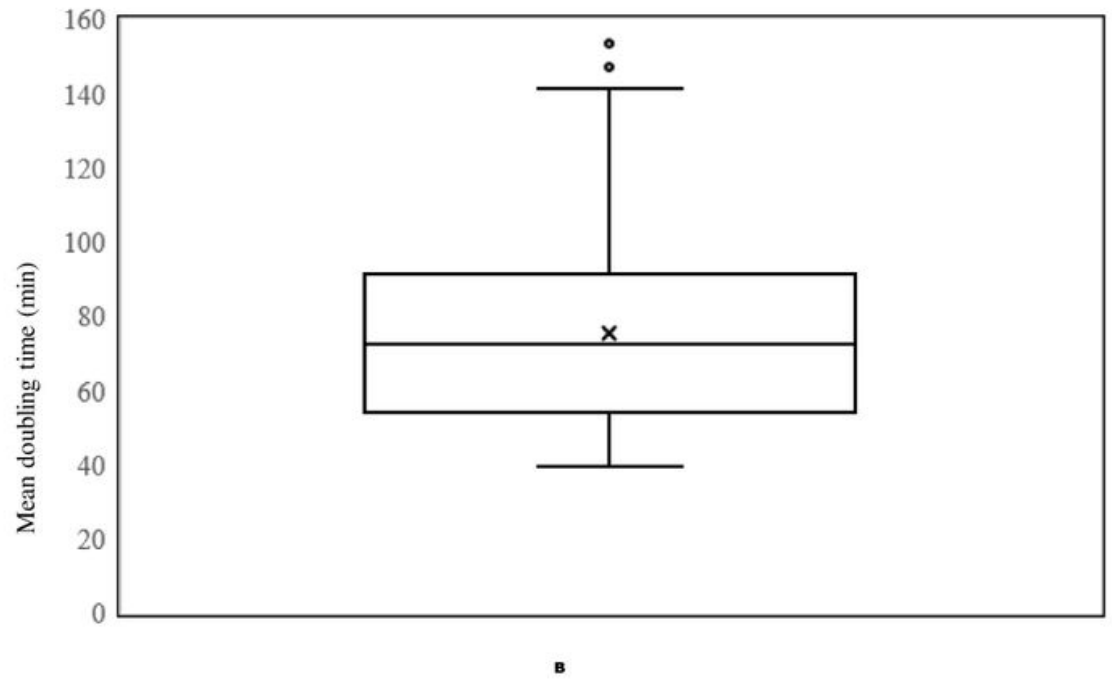

Figure 2

(a) Mean doubling time of the isolated strains. Isolates were grown overnight and subcultured to fresh THY broth and absorbance was measured every one-hour interval. Doubling time was calculated based on two OD values taken from the logarithmic phase of the growth by using the formula, $r=\ln$ [OD2/OD1]/(T2-T1) and represents the average value of at least two measurements. We have included first 40 strains (SN1 to SN40) for simplicity and included all the strains in the supplementary Table. (b) Box plot showing the summary of the mean doubling times of the isolated strains $(n=209)$. 


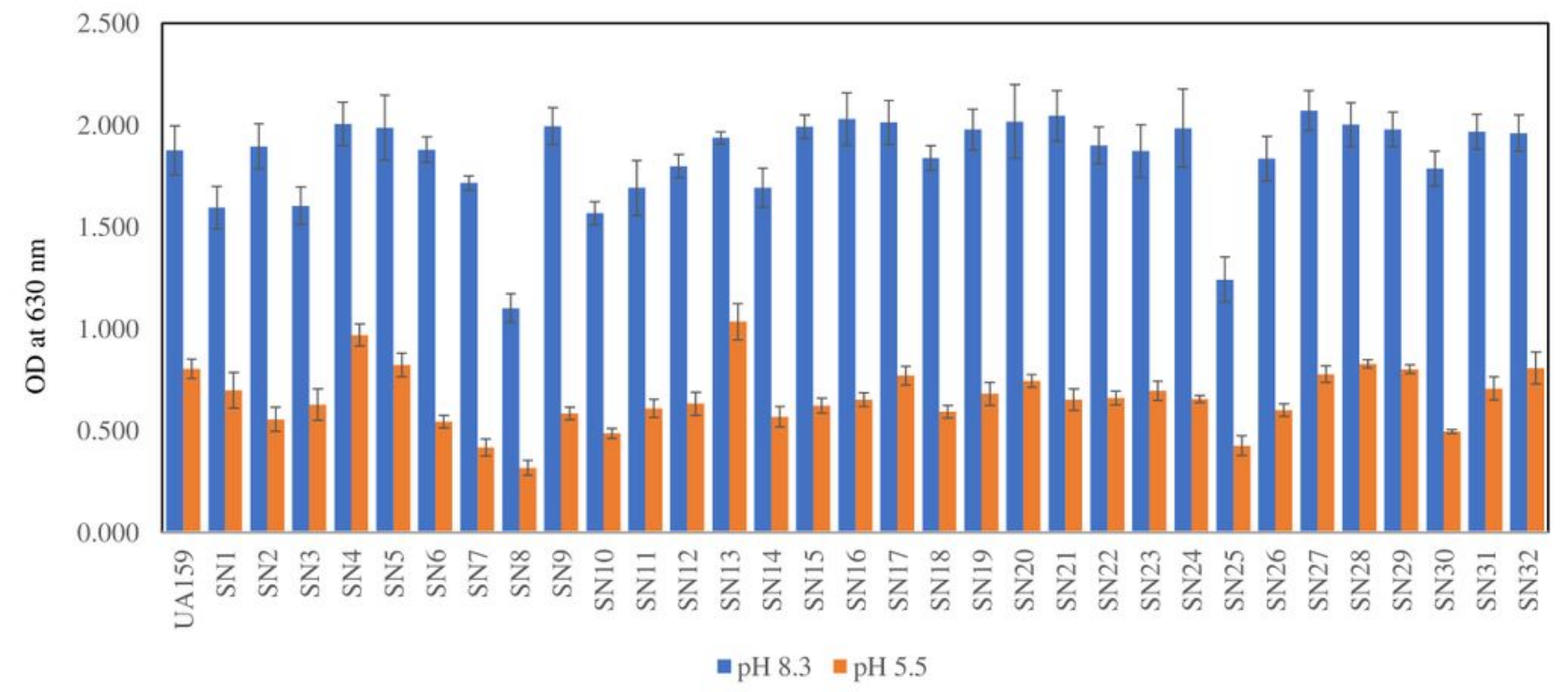

Figure 3

Acid tolerance of the isolated strains. Isolates were grown overnight in THY medium and subcultured to fresh THY broth either at $\mathrm{pH} 8.3$ or $\mathrm{pH} 5.5$ and growth was monitored for 24-hour period. Error bar represents the standard deviation. We have included first 32 strains (SN1 to SN32) for simplicity and included all the strains in the supplementary Table.

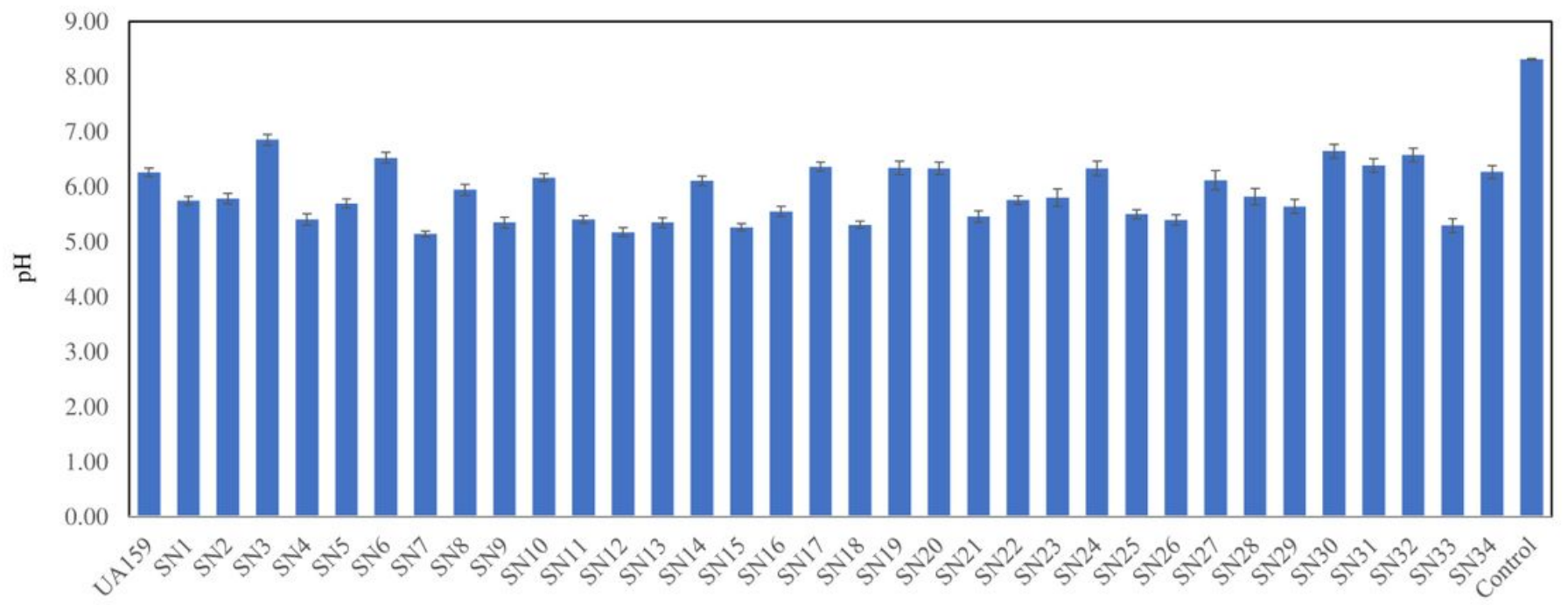

Name of the clinical isolates

\section{Figure 4}

Acid production by the isolated strains. Isolates were grown overnight in THY medium and subcultured to THY broth and the $\mathrm{pH}$ was measured every 24-hour intervals with a $\mathrm{pH}$ meter. Error bar represents the 
standard deviation. We have included first 34 strains (SN1 to SN34) for simplicity and included all the strains in the supplementary Table.

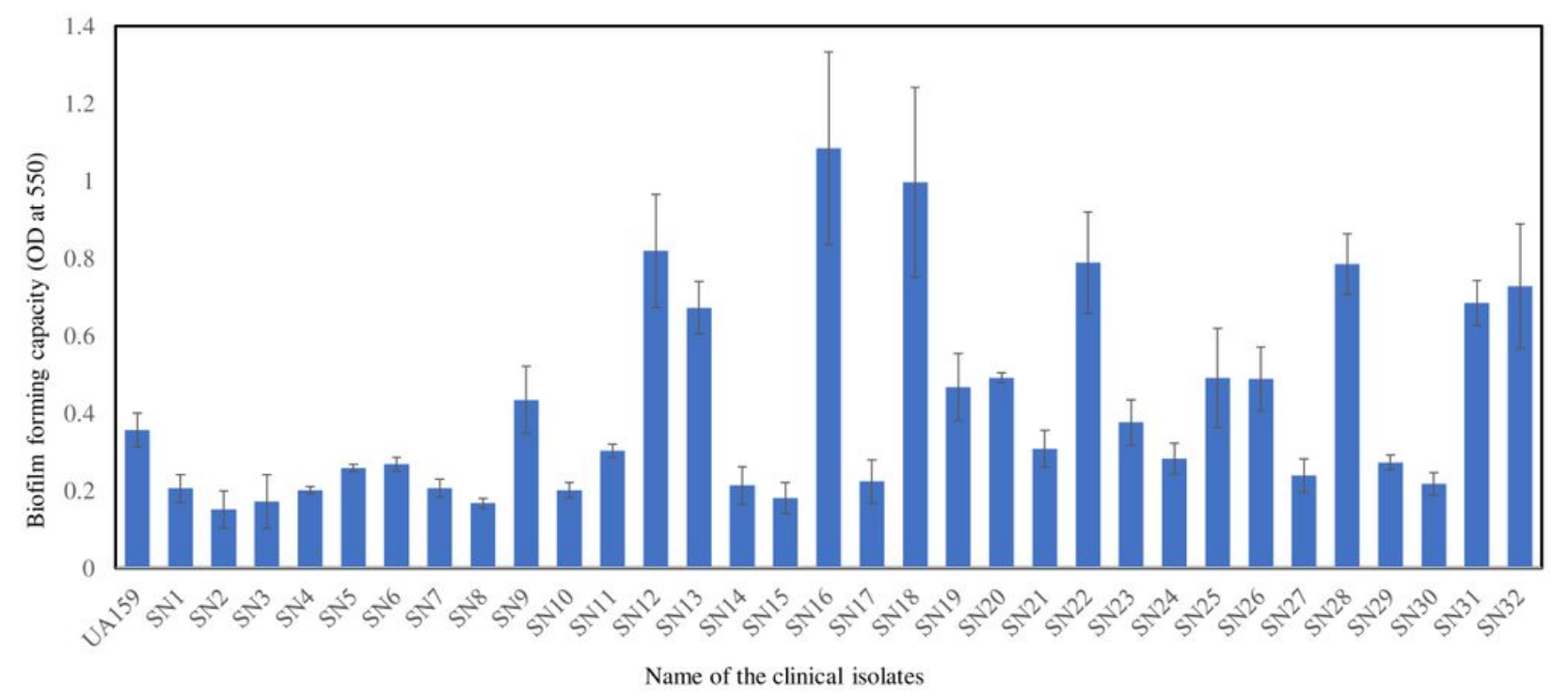

Figure 5

Biofilm formation by the isolated strains. Bacteria were grown in THY medium supplemented with $1 \%$ sucrose for 48 hours in 24 well plates. After the growth, supernatants were discarded and stained with crystal violet and washed with distilled water. Cells were resuspended into ethanol and absorbance values were taken at $550 \mathrm{~nm}$. Error bar represents the standard deviation. Each experiment was performed in triplicates. We have included first 32 strains (SN1 to SN32) for simplicity and included all the strains in the supplementary Table. 


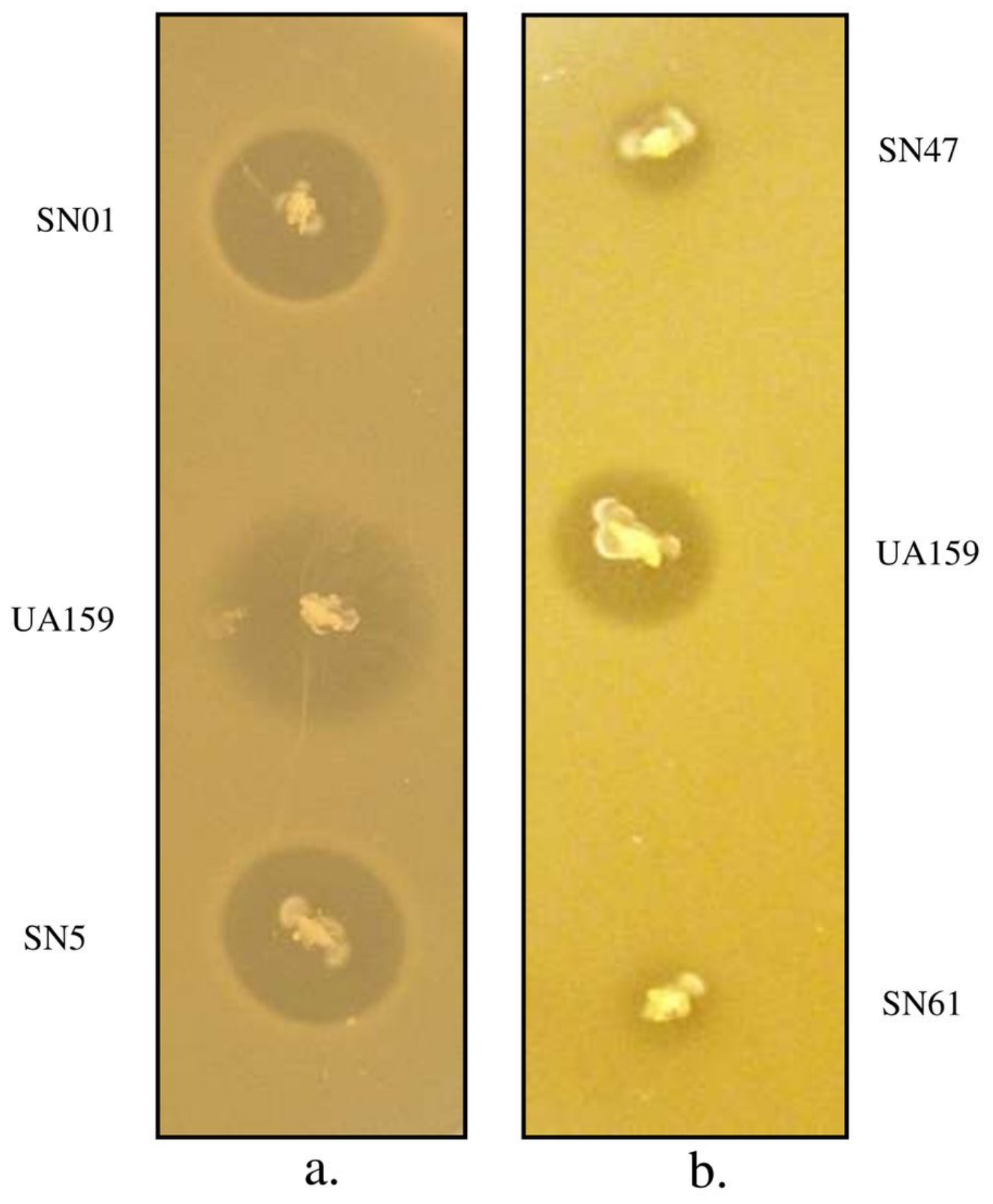

\section{Figure 6}

Bacteriocin production by the clinical isolates. A single colony of the clinical isolates were stabbed into the THY agar and incubated for 24-hour. Indicator bacteria were grown overnight and overlaid on the THY agar plate seeded with the clinical isolates as soft agar. S. pyogenes SN15 (a) and L. lactis (b) were used as indicator bacteria. Overlaid plates were then incubated overnight under same conditions and the diameter of the zones of inhibition around the producer bacteria was measured. Assays were repeated at least three times and a representative plate is shown. Supplementary Fig 1 . Colony morphology of the 
isolated strains on mitis-salivarius-bacitracin agar. Oral samples were collected from plaque surface of patients with dental caries using sterile toothpick and suspended in $1 \mathrm{ml}$ phosphate buffer saline (PBS) buffer. $100 \mu \mathrm{l}$ of the sample was spread on the mitis salivarius agar supplemented with $0.5 \mathrm{lU} / \mathrm{mL}$ bacitracin (Sigma, USA) and incubated at microaerophilic condition at $37^{\circ} \mathrm{C}$ for 48 hours.

\section{Supplementary Files}

This is a list of supplementary files associated with this preprint. Click to download.

- SupplementaryFigure1.tiff

- SupplementaryTable1.docx

- SupplementaryTable2.pdf 